\title{
Pulmonary Erythema Migrans?
}

\author{
Oxana Munteanu ${ }^{\mathrm{a}}$ Dumitru Chesov ${ }^{\mathrm{a}}$ Doina Rusu $^{\mathrm{a}}$ Christoph Lange $^{\mathrm{b}, \mathrm{c}}$ \\ Victor Botnaru ${ }^{a}$ \\ a Division of Pneumology, Department of Internal Medicine, State Medical University of Medicine and \\ Pharmacy 'Nicolae Testemitanu', Chisinau, Republic of Moldova; ${ }^{\text {b}}$ Division of Clinical Infectious Diseases, \\ Borstel Research Center, Borstel, and ' German Center for Infection Research (DZIF), Germany
}

\section{Key Words}

Ground-glass opacity · Reversed halo sign · Cryptogenic organizing pneumonia

A 27-year-old, previously healthy woman complained of gradually worsening fatigability, sweats and a cough over a period of 4 weeks. A chest X-ray revealed multiple, bilateral ring-shaped opacities of variable sizes $(5-12 \mathrm{~cm})$ and areas of lung consolidation (fig. 1a). A chest CT (fig. 1b-d) revealed spherical lesions with solid consolidation or different stages of central clearance of the infiltration (a reversed halo sign). Cavitations were not present. The bronchoalveolar-lavage fluid differential cell count was: $25 \%$ alveolar macrophages, $54 \%$ lymphocytes, $16 \%$ polymorphonuclear granulocytes and 5\% eosinophils. Transbronchial biopsies revealed intra-alveolar buds of granulation tissue. The diagnosis of cryptogenic organizing pneumonia was considered and therapy with prednisolone $30 \mathrm{mg} /$ day was initiated. Repeat CT after 10 weeks of steroid therapy showed a near-complete resolution of these findings.

The 'reversed halo sign', 'atoll sign' or 'fairy ring sign' is defined as central ground-glass opacity surrounded by a ring or crescent-shaped area of consolidation of at least
$2 \mathrm{~mm}$ thickness [1]. It is a relatively specific sign for cryptogenic organizing pneumonia $[1,2]$, but the differential diagnosis list should also include: bacterial pneumonia, lymphomatoid granulomatosis, Wegener's granulomatosis, tuberculosis, mucormycosis, paracoccidioidomycosis, sarcoidosis, cancer and pulmonary infarction. Although the pathogenesis of the 'reversed halo sign' is not yet understood, a recent tick-bite (Ixodes ricinus) is not a recognized risk factor. Identification of this imaging feature in correlation with clinical data, medical history and laboratory investigation results serves as a useful clue for establishing an accurate diagnosis.

\section{References}

1 Voloudaki AE, Bouros DE, Froudarakis ME, Datseris GE, Apostolaki EG, Gourtsoyiannis NC: Crescentic and ring-shaped opacities. CT features in two cases of bronchiolitis obliterans organizing pneumonia (BOOP). Acta Radiol 1996;37:889-892.

$>2$ Cottin V, Cordier JF: Cryptogenic organizing pneumonia. Semin Respir Crit Care Med 2012;33:462-475.

\section{KARGER}

E-Mail karger@karger.com

www.karger.com/res
(C) 2014 S. Karger AG, Basel

0025-7931/14/0873-0252\$39.50/0
Prof. Dr. Christoph Lange

Division of Clinical Infectious Diseases, Medical Clinic German Center for Infection Research (DZIF), Tuberculosis Unit Research Center Borstel, Parkallee 35, DE-23845 Borstel (Germany) E-Mail clange@fz-borstel.de 
Fig. 1 a A chest X-ray shows multiple, bilateral, ring-shaped opacities of varying sizes $(5-12 \mathrm{~cm})$ and areas of lung consolidation. b-d Chest CT scans show spherical lesions with solid consolidation or different stages of central clearance of the infiltration (a reversed halo sign).
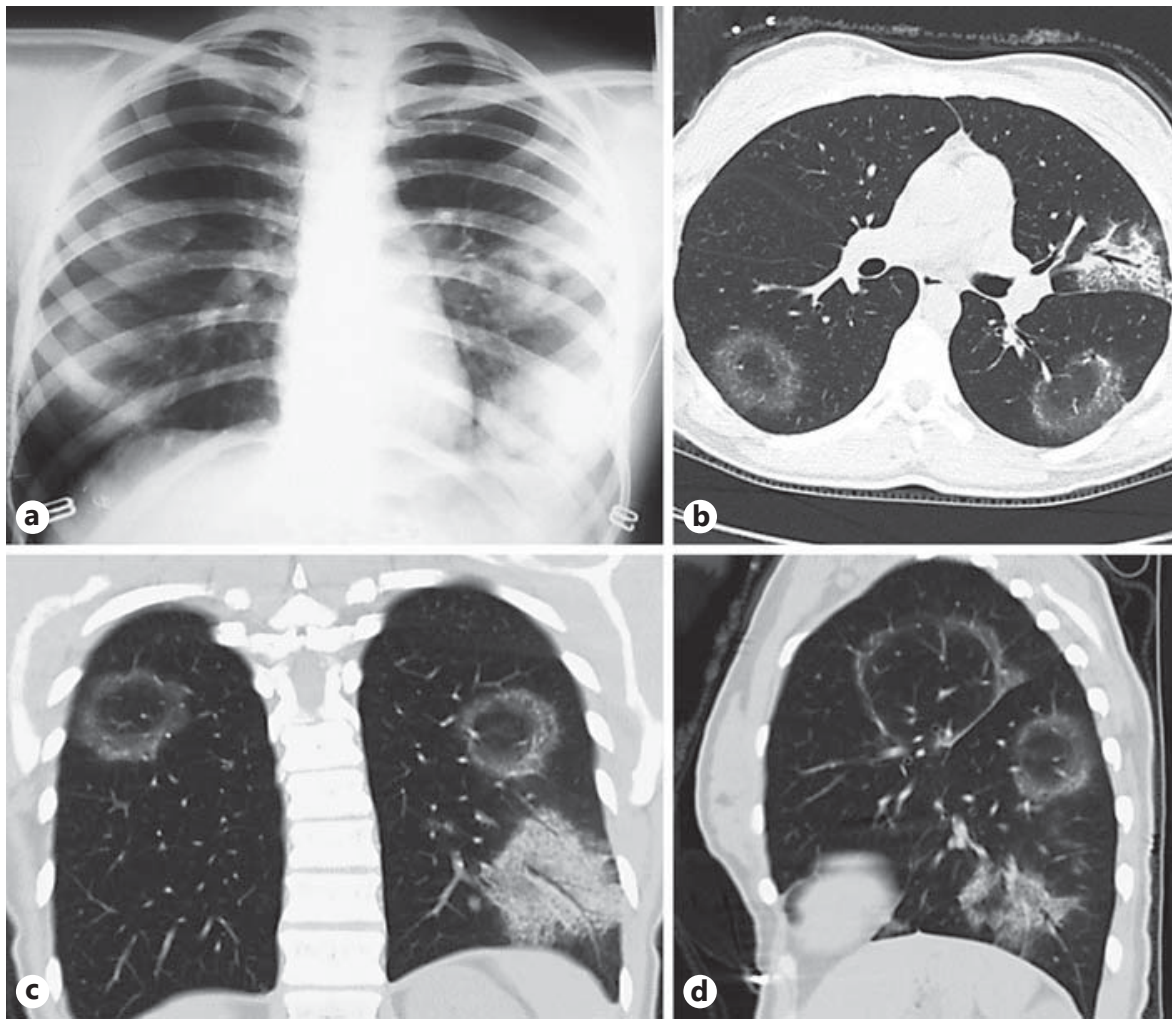